\title{
Ecological Flow Regime and its Satisfactory Degree Assessment Based on an Integrated Method
}

\author{
Wei Xu' ${ }^{1 *}$, Zengchuan Dong', Zhenchun $\mathrm{Hao}^{2}$, Li Ren ${ }^{1,2}$, \\ Wenzhuo Wang ${ }^{1}$, Dayong Li ${ }^{1}$ \\ ${ }^{1}$ College of Hydrology and Water Resources, Hohai University, Nanjing, China \\ ${ }^{2}$ State Key Laboratory of Hydrology-Water Resources and Hydraulic Engineering, Hohai University, \\ Nanjing, China
}

Received: 5 August 2018

Accepted: 8 October 2018

\begin{abstract}
Ecological flow regime (EFR) evaluation is essential in river ecosystem protection. To evaluate and maintain EFR under a changing environment reasonably, an integrated method based on both the monthly $7 \mathrm{Q} 10$ method and biological analysis method was put forward for its simple modelling and small data requirement, and then reasonable EFR was obtained after a reasonable check by the Tennant method. Meanwhile, the concept and quantitative formula of the ecological flow regime satisfactory degree (EFRSD) were recommended and successfully applied in the Luanhe River. The results showed that the flow regime of the Luanhe was significantly interrupted by human activities after 1979, and EFRSD has been distinctly damaged since 1998; after 1979, from good to bad, the EFRSD of the Luanhe was the upstream, midstream and downstream. Then the driving forces leading to the Luanhe's EFRSD deterioration that included reduction in the natural rainfall, construction and operating of water conservation projects, and overexploitation of groundwater were discussed and analyzed. Finally, countermeasures for the ecological rehabilitation of the river were pertinently put forward.
\end{abstract}

Keywords: ecological flow regime, integrated method, satisfactory degree, ecological rehabilitation

\section{Introduction}

Stable flow regimes are valuable to human society because of their key roles in climate regulation, river dredging, transporting nutrients, hydro-electric power generation and maintaining the diversity of aquatic organisms [1-2]. However, in the last few decades, the river flow regime has undergone a profound change due to climate change and human interference [3-13].

*e-mail: xuwill@hhu.edu.cn
The sharp reductions in rainfall and the increase of extreme weather events such as extreme drought and climatic warming have directly or indirectly affected the regularity of flow regime [14-17]. Meanwhile, the construction and operation of water conservancy projects, particularly dams and inter-basin water diversion projects, have destroyed the continuity of material flows, energy flows and information flows between the upstream and the downstream of the dams, resulting in the natural flow regime not being maintained $[18,19]$. Stream betrunking has even become a common phenomenon in some regions over the past decades, such as the Yellow River Basin and the Hai River Basin 
in China. And it is well documented that both the two rivers' flow regimes, sediment regimes and water temperature regimes have been unavoidably altered [2022]. From the perspective of the abiotic environment, due to the significant changes of flow regime and even stream betrunking, the river ecosystem cannot maintain the basic functions for the abiotic environment, such as climate regulation, river dredging and transporting nutrients. From the perspective of biological water requirement, according to Shelford's law of tolerance, when the flow regime is insufficient or too large, and beyond the tolerance limit of some species, these species cannot live normally, or even go extinct, which will lead to non-normal ecological succession of other related species, finally resulting in the river ecological system deterioration.

Flow regime is one of the key factors that affect river ecosystem health. With serious river ecosystem degradation, the concept of ecological flow regime (EFR) has been put forward in the western United States in the 1940s, and has been a research hotspot ever since. In the following years, the research of EFR developed rapidly with the development of social economy and the increase in human activity. And in the 1980s, Australia, England, South Africa and many other regions started relevant research. Three kinds of important approaches for estimating EFR appeared as follows: (1) hydrological-based, (2) hydraulic-based and (3) biological-based. Among the above approaches, the hydraulic-based approach and biological-based approach are quite complex, and many hydraulic parameters and biological-related information must be measured. However, in many regions, it may be difficult to implement for the lack of related large data.

The hydrological-based approach usually uses simple hydrological indicators to produce good fish habitat in rivers, such as the percentage of the mean annual flow. Furthermore, the Tennant [23], 7Q10 [24], minimum mean monthly flow [25], Texas [24], and basic flow [27] methods are the representative methods of this approach. At present, the Tennant method, which was developed after measurements of width, average depth, and average velocity in many streams, has been the most widely used method applied to warm- and cold-water streams in many countries. It is based on historical records of discharge, and takes the percentage of the average annual flow or the percentage of the average flow in specific periods (the whole year is divided into several periods, such as flood period and non-flood period) as EFR [23]. And it is documented that $10 \%$ of the average annual flow is the minimum instantaneous flow needed to sustain short-term survival in many regions, such as the Yellow River and Luanhe River in China [28, 29]. But it should also be mentioned that effective percentage value is theoretically obtained according to the corresponding relationship between the mean flow and the river eco-environmental conditions. And attempts to transfer the threshold flow numbers directly to other countries without re-calibrating for different ecological environments are wrong. Therefore, the key to estimating EFR by the Tennant method is to determine a reasonable and effective percentage value.

The 7Q10 method, based on both hydrological parameters and quality factors (river self-purification capacity, for example), is a 10-year annual low-flow statistics based on the smallest values of mean discharge computed over any 7 concecutive days during the annual period. However, this method was limited in the actual operation process in China, because of its strict standard. Thus, the national standard (GB3839-83, China) recommended that the mean flow of the driest month in the last 10 years or the year with an assurance rate of $90 \%$ be regarded as EFR.

It is easy to find that the computing processes of both methods mentioned above are based on historical records of flow. And for natural river systems, both methods are suitable for calculating EFR. However, in human-impacted river systems, measured flow data are dramatically influenced, especially in the most recent 40 years by social and economic water use, reservoir building and operating, overexploitation of groundwater and other human activities. The flow statistics by the these recent data are usually smaller [30] and cannot be used to estimate ecological flow requirements. Besides, the partial flow which is regulated and consumed by these human activities and its actual annual distribution are difficult to obtain. So calculating EFR by reduction of runoff series is very complex, and this method is not suitable for areas lacking social and economic water consumption data. In order to avoid the complex problem of runoff reduction, and considering hydrological parameters, quality factors and aquatic life protection, this paper proposes an integrated method composed by the improved monthly 7Q10 hydrological method and biological analysis method to estimate EFR.

EFR is the flow process needed to maintain the basic ecological functions of a certain water area. Determining EFR is the basis to protect river ecosystem functions. To better protect and restore the river ecosystem, the ecological flow regime satisfactory degree (EFRSD) can be defined as the percentage of days (months or years), with ecological flow requirements being fulfilled for a stream section or a river in a research period. And it is clear and easy for stakeholders and policy makers to understand the river EFR state according to EFRSD, which could help them make correct decisions on river policy. With a surprising economic growth rate in the last forty decades, China has serious riverrelated problems intensified by human activities and climate change [31]. Luanhe River is located in northern China, which has a dense population and developed economy. And it serves as a water source for Tianjin and Tangshan - two important cities near the basin. In recent years, with the climate variation and unreasonable development and utilization of water resources, the flow regime in Luanhe River changed significantly, which in turn threatened the water supply, food security and ecological health of the river basin [32]. The proposed 
integrated method was applied in the Luanhe River upstream, midstream and downstream, and EFRSD was computed and analysed respectively. Accordingly, the reasons for the Luanhe River EFRSD's variation were discussed and some countermeasures were pertinently put forward for the river ecological rehabilitation.

\section{Material and Methods}

\section{Study Area Background}

The Luanhe River originates from Bayanguer Mountain, which is located in the north of China, near the capital, Beijing, and it flows southeastwards $888 \mathrm{~km}$ through 3 provinces (Inner Mongolia, Liaoning and Hebei) before emptying into the Bo Sea (Fig. 1). The drainage area of the Luanhe is $44750 \mathrm{~km}^{2}$, among which mountains account for 98.2\% (43940 $\left.\mathrm{km}^{2}\right)$, and plains account for the rest $\left(810 \mathrm{~km}^{2}\right)$. Luanhe runoff is relatively high among rivers in northern China, and its mean annual natural runoff is more than $4 \times 10^{9} \mathrm{~m}^{3}$. However, since the completion and operation of Panjiakou, Daheiting, and Taolinkou reservoirs, plus other large-scale major water conservancy projects in the mainstream and tributaries of the Luanhe, it has been the water resources area of Tianjin and Tangshan. And the water demand in these two cities continuously increases with the regional economy. In addition, the annual average amount of shallow groundwater downstream of the Luanhe is $8.9 \times 10^{8} \mathrm{~m}^{3}$, of which $96.0 \%\left(8.54 \times 10^{8} \mathrm{~m}^{3}\right)$ has been exploited. Strong groundwater resources development activities have drastically changed the balance between surface water and groundwater [33]. And overexploitation of groundwater has been another factor leading to the flow decreasing. With the overexploitation of groundwater, the construction and operation of reservoir dams and inter-basin water diversion projects in the Luanhe, great changes have occurred to the flow regimes and sediment regimes in the lower reaches. These damaged the physical forms of channels, and caused ecological function degeneration and biodiversity loss [34]. To access the actual river health status of the Luanhe objectively, a fuzzy matter-element extension assessment model has been successfully built and applied. And the Luanhe is in an unhealthy state at present, as demonstrated by the following indexes: estuary runoff, ecological flow rate, sediment transport change rate, longitudinal connectivity, water quality compliance rate and aquatic life [33]. Consequently, the river's EFR and analyzing EFRSD are of particular importance in studying the more prominent conflict between ecology and development, which could provide useful information for stakeholders and policy makers to conduct basin ecological rehabilitation and allocation of water resources.

\section{Calculation of EFR Based on the Integrated Method}

The integrated method this paper proposed to calculate EFR includes 7 steps:

1) Evaluate the river ecosystem health status and determine its ecological protection objectives, especially for the endemic aquatic life.

2) Divide the natural period (the impact of human activities on runoff is weak, similar to the natural

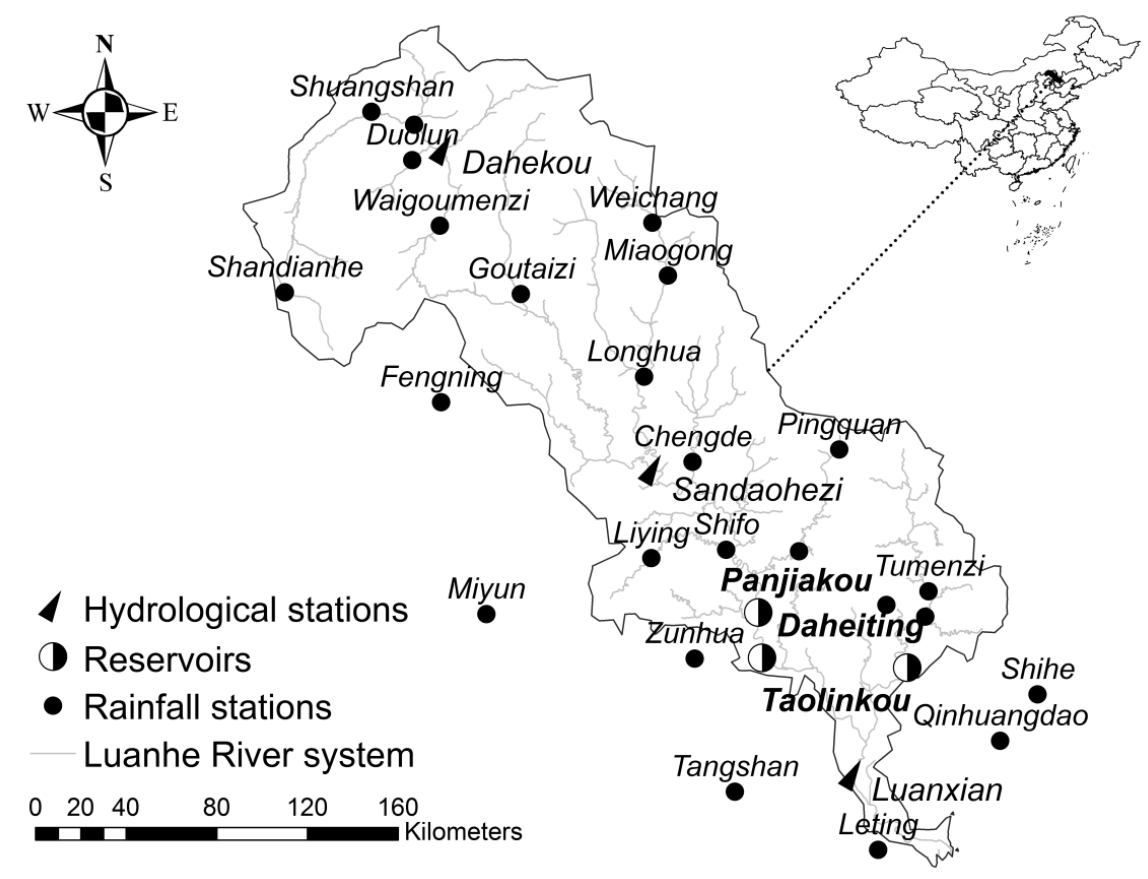

Fig. 1. Sketch of Luanhe River. 
period) and human-impacted period of the flow through the precipitation-flow double mass curve method.

3) Use the long series of annual precipitation data of the whole basin to arrange the frequency by Pearson Type-III Distribution Curve-fitting method, then determine the design precipitation of $P=90 \%$.

4) Look for the years (two or more) in the natural period that the year's precipitation is the same as or similar to the design precipitation of $P=90 \%$, then regard these years as the representative hydrological years $(P=90 \%)$.

5) Calculate EFR by monthly $7 Q 10$ method using the measured flow data of the representative hydrological years $(P=90 \%)$ after (4).

6) Determine the ecological flow requirements for the endemic aquatic life.

7) Reasonable check by both the biological analysis and Tennant method with the measured flow data of the natural period.

8) Determine the final EFR in each section, respectively, using the outer envelope method.

The methods presented in this paper include the double mass curve method, Pearson-III distribution curve-fitting method, 7Q10 method, biological analysis method and Tennant method. These methods are widely used in the realm of hydrology and water resources.

\section{Double Mass Curve Method}

The double mass curve method is a simple, direct and widely used method for testing the consistency and trend analysis of the hydrological and meteorological factors $[35,36]$. The so-called double mass curve is that drawing a relation line between continuous cumulative values of a variable and another variable in the same period in Cartesian coordinates. In precipitationflow double mass curve, cumulative precipitation is regarded as a reference variable (precipitation process is a natural change and the impact of human activities on it is weak in a limited short period of time), while the cumulative flow is affected by both human activities and precipitation [32]. If there are some intensive human activities acting on the flow, then there will be one or more inflexion points on the double mass curve. And the study period can be divided into the natural period and human impacted period according to the analysis of the inflexion points.

\section{Pearson Type-III Distribution Curve-Fitting Method}

Pearson Type-III distribution is a type of distribution recommended in Regulation for Hydrologic Computation of Water Resources and Hydropower Projects by the Ministry of Water Resources of China (SL278-2002, China). For a continuous observed data series $\left(x_{1}, x_{2}, \ldots, x_{n}\right)$, the curve-fitting method is divided into the following 3 steps: (1) plot the empirical probability points; (2) draw the theoretical frequency curve; (3) if the points do not match the fitting curve well, then adjust the parameters $\left(C_{r}, C_{S}\right)$ until it has a nice fitting result.

In this method, the empirical probability equation is chosen:

$$
P_{m}=\frac{m}{n+1}
$$

...where $n$ is the sample number and $m$ is the order of samples arranged from big to small: $\left(x^{*}, x^{*}{ }_{2}, \ldots, x_{n}^{*}\right)$.

The initial values of the Pearson Type-III distribution parameters are calculated by the moment method:

$$
\begin{gathered}
\bar{x}=\frac{1}{n} \sum_{i=1}^{n} x_{i} \\
K_{i}=\frac{x_{i}^{*}}{\bar{x}} \\
C_{V}=\sqrt{\frac{1}{n-1} \sum_{i=1}^{n}\left(K_{i}-1\right)^{2}} \\
C_{S}=\frac{\sum_{i=1}^{n}\left(K_{i}-1\right)^{3}}{(n-3) C_{V}^{3}}
\end{gathered}
$$

\section{Monthly 7010 Method}

7Q10 means the annual minimum 7-day average flow rate that occurs with an average frequency of once every 10 years. And the specific water-quality criteria applicable at the 7Q10 minimum flow condition includes the aquatic life criteria dissolved oxygen (DO), $\mathrm{pH}$, temperature, turbidity, and toxicity as well as the human health criteria for non-carcinogens.

The monthly 7Q10 method is to take the average flow of any 7 consecutive days whose streamflow is the smallest in a month as the monthly ecological flow.

\section{Biological Analysis Method}

The survival, growth and reproduction of aquatic organisms requires certain flow regime conditions. Look for the typical aquatic organisms such as the rare endemic fish in the study area, and determine the ecological flow requirements for the endemic aquatic life according to their life habits.

\section{Tennant Method}

Take the percentage of the average annual flow or the percentage of the mean flow in the same periods (the whole year being divided into flood period and 
the non-flood period) as EFR [23]. And it has been documented that the instantaneous flow should be at least $10 \%$ of the average flow (AF) in order to sustain the aquatic organisms' short-term survival. Under this flow condition, the water depths and velocities are decreased significantly; the riverbed is about one-third exposed; fish are crowded into the deeper pools and riffles are too shallow for large fish to pass. To maintain good aquatic life habitat, $30 \% \mathrm{AF}$ is required. Under this flow condition, widths, depths, and velocities are generally satisfactory; stream banks provide some cover; and large fish can pass most riffles. In addition, $60-100 \%$ AF is needed for providing optimum habitat and $200 \% \mathrm{AF}$ is the maximum flow [35]. Therefore, to recommend a flow regime concerned with good aquatic life habitat, the flows can be described into 8 grades as follows: (a) maximum, (b) optimum, (c) outstanding, (d) excellent, (e) good, (f) fair, (g) minimum and (h) severe degradation (Table 1).

\section{Calculating EFRSD}

After obtaining EFR of each section, EFRSD in each section during a human-impacted period can be calculated. Its computation formula is as follows:

$$
p_{s}=\frac{d}{D} \bullet 100 \%
$$

...where $p_{s}$ is the EFRSD in a section; $D$ is the total number of days in the evaluation period; and $d$ is the number of days which ecological flow requirement is fulfilled in $D$.

Then the whole river's EFRSD can be calculated using:

Table 1. Tennant method for prescribing instream flow regimes for fish, wildlife, recreation and related environmental resources. For Luanhe River the flows recommended for flood period are recommended for May through September and the non-flood period flows are recommended for October through the next April.

\begin{tabular}{|c|c|c|}
\hline \multirow{2}{*}{ Description of flows } & \multicolumn{2}{|c|}{$\begin{array}{c}\text { Recommended ecological } \\
\text { flow regimes (Percent of average } \\
\text { annual flow) }\end{array}$} \\
\cline { 2 - 3 } & $\begin{array}{c}\text { Non-flood period } \\
\text { Maximum }\end{array}$ & Flood period \\
\hline Optimum & 200 & 200 \\
\hline Outstanding & 40 & 80 \\
\hline Excellent & 30 & 60 \\
\hline Good & 20 & 50 \\
\hline Fair & 10 & 40 \\
\hline Minimum & 10 & 30 \\
\hline Severe degradation & $0-10$ & 10 \\
\hline
\end{tabular}

$$
p_{r}=\frac{1}{n} \sum_{i=1}^{n} p_{s}
$$

...where $p_{r}$ represents the whole river's EFRSD and $n$ is the number of the selected hydrological sections.

\section{Data Sources}

Sources of data used in this paper are as follows:

\section{Precipitation Data}

Monthly time series of precipitation $(\mathrm{mm})$ data from 1957 to 2011 at Duolun, Fengning, Weichang, Miyun, Chengde, Zunhua, Qinglong, Baichengzi, Goutaizi, Kuancheng, Liying, Miaogong, Pingquan, Shandianhe, Shifo, Shihe, Shuangshan, Shuangshanzi, Tumenzi, Longhua, Waigoumenzi, Qinhuangdao, Tangshan and Leting (Fig. 1) were collected from the National Climate Centre of China Meteorological Administration (CMA), China. The homogeneity and reliability of the monthly meteorological data have been checked and firmly controlled by the CMA before their release.

\section{Flow Data}

Daily time series of flow discharge $\left(\mathrm{m}^{3} / \mathrm{s}\right)$ data from 1957 to 2011 at Dahekou, Sandaohezi and Luanxian (Fig. 1) were collected from the Haihe River Water Resources Commission (HWRC), China. The homogeneity and reliability of the hydrological data have been checked and firmly controlled by the HWRC before their release and with no missing data.

\section{Quantity of Water Entering into the Sea}

Annual time series of estuary runoff $\left(\times 10^{8} \mathrm{~m}^{3}\right)$ data from 1957 to 2011 were collected from the research results from the comprehensive water resources evaluation of Hebei Province, China, which were computed by water balance method.

\section{Reservoir Information}

Large and medium-sized reservoir data that includes the reservoir's location, type, catchment area, total reservoir capacity, utilizable capacity and built time from 1957 to 2011 were collected from the HWRC, China.

\section{Results and Discussion}

\section{EFR Results of Luanhe River}

According to Xu's evaluation results, the Luanhe is in an unhealthy state at present, as demonstrated by the following indexes: estuary runoff, ecological 


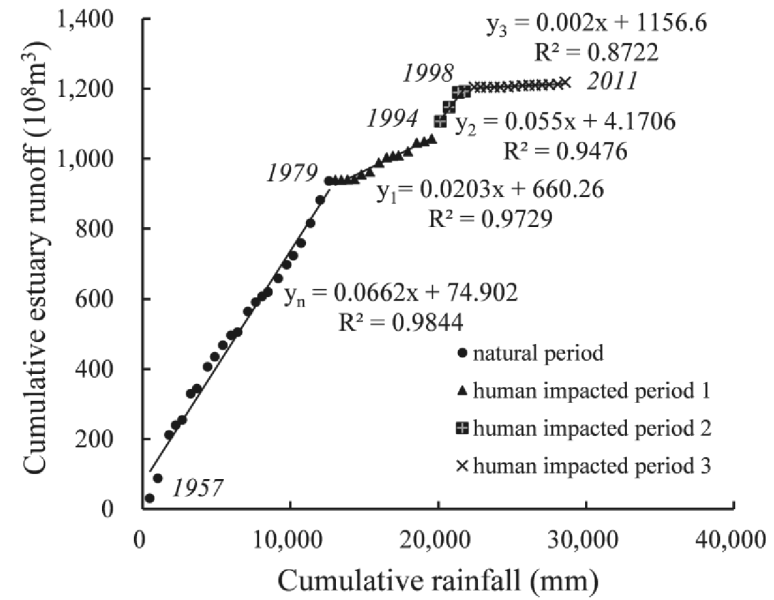

b)

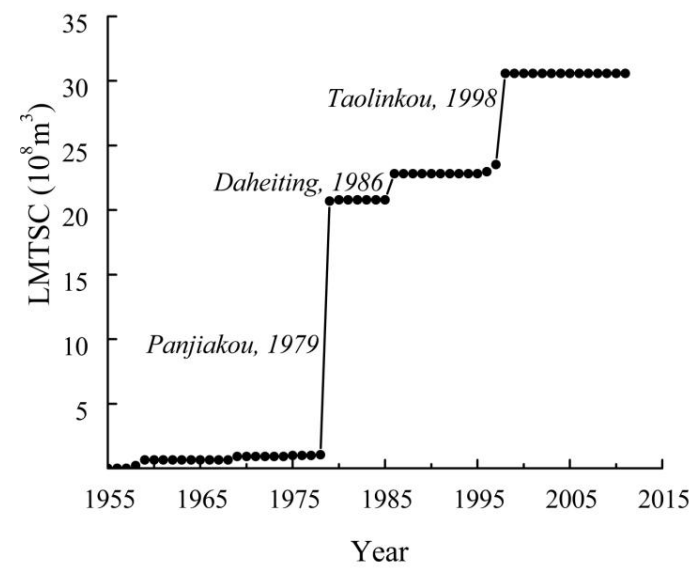

Fig. 2. Comparisons between precipitation-estuary flow double mass curve a) and large and medium-sized reservoirs total storage capacity b) from 1955 to 2011 of Luanhe River. flow rate, sediment transport change rate, longitudinal connectivity, water quality compliance, and aquatic life [33]. In addition, brachymystax lenok is a rare fish species in the upper and middle reaches of the Luanhe. Its spawning season is from mid-April to June, and it requires that the flow in this period is not less than $0.2 \mathrm{~m}^{3} / \mathrm{s}$ [38]. Meanwhile, the crucian carp is the endemic species in the lower reaches area. Its spawning season is from May to July, and it requires that the flow be larger than $6.198 \mathrm{~m}^{3} / \mathrm{s}$ during its initial breeding period [39]. So, in order to improve the factors that affect the river ecosystem health, restoring the river EFR is particularly important for sediment transport, increasing estuary runoff, water purification and protection of aquatic life.

The watershed annual average precipitation was calculated by the Thiessen polygon method based on the annual precipitation data from the 24 rainfall stations above. Fig. 2a) presents the precipitation-flow double mass curve (1957 to 2011) of the Luanhe River Basin. And the precipitation here is the annual precipitation in the basin, and the flow is the annual estuary flow in the outlet of the basin. Then the first inflexion point on the precipitation-estuary flow double mass curve can be used to distinguish the effect of human activities on flow. From Fig. 2a) we can see that the curve is almost a rising straight line before 1979, and the curve deviates from the original trend after 1979. It indicates that the flow regime was strongly interrupted by human activities after 1979. So the river flow series can be divided into two stages as follows: (1) 1957 to 1979 and (2) 1980 to 2011. The former is regarded as the natural period, while the latter is regarded as the human impacted period. Otherwise, there are another 2 inflexion points: 1994 and 1998. This indicates that the

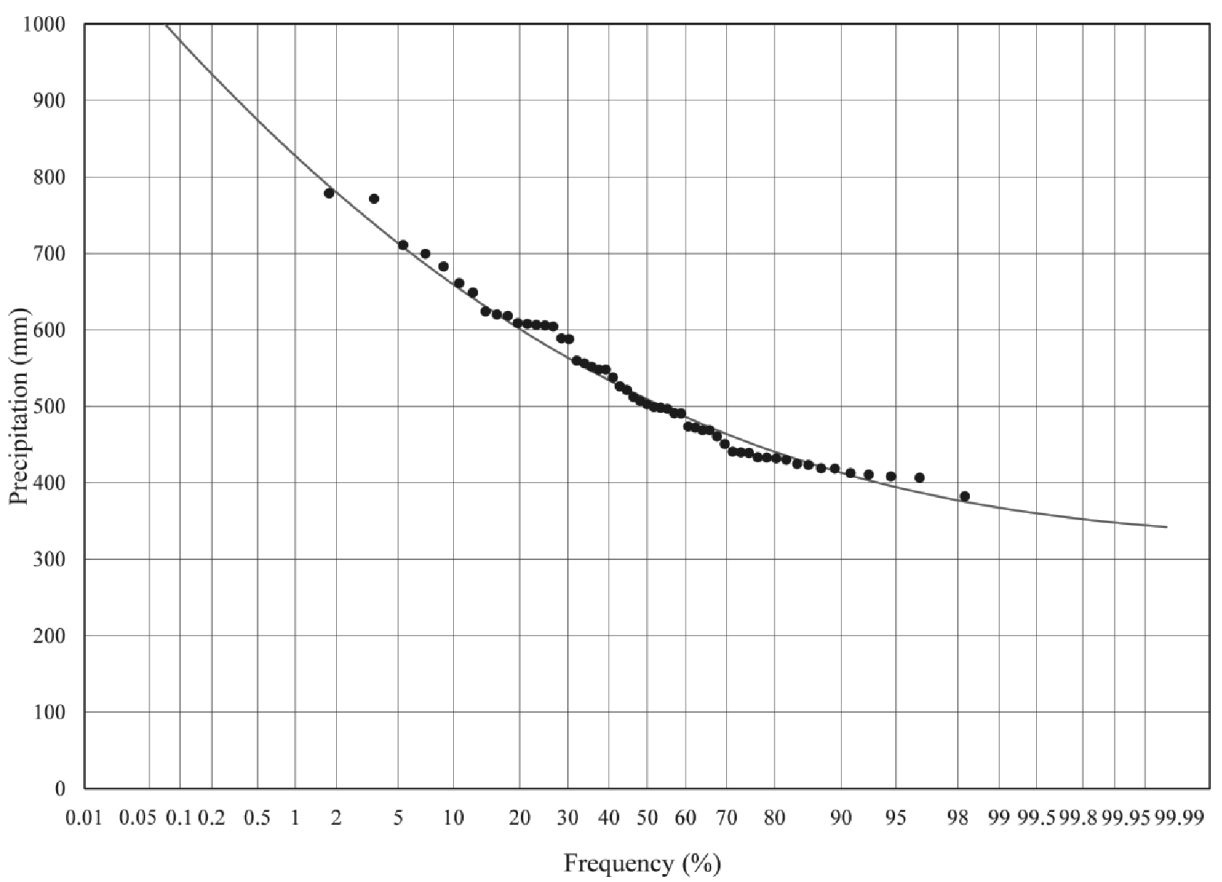

Fig. 3. Precipitation frequency curve of Luanhe River. 
human impacted period can also be divided into three stages: (1) 1980 to 1994 , (2) 1995 to 1997 and (3) 1998 to 2011 .

For the flow regime that has been significantly affected by human activities since 1979, the frequency analysis of the measured flow series 1957-2011 is of little significance. However, human activities have less effect on precipitation than flow in a short period. So this paper determined the designed precipitation with an assurance rate of $90 \%$ through Pearson Type-III distribution frequency analysis, which is based on a long series of the whole basin's precipitation data. And the designed precipitation with an assurance rate of $90 \%$ in the Luanhe was $414 \mathrm{~mm}$ (Fig. 3). And the years 1971 and 1972 were selected as the representative hydrological years of the Luanhe $(\mathrm{P}=90 \%)$. According to the related literature, there were no dry river phenomena and no unusual aquatic deaths in this basin in 1971 and 1972, so 1971 and 1972 were the reasonable alternatives. In this paper, Dahekou, Sandaohezi and Luanxian were selected as the representative hydrological sections for the Luanhe upstream, midstream and downstream, respectively (Fig. 1). And the EFR of each section computed by the monthly $7 \mathrm{Q} 10$ method were given in Tables 2-4, respectively.

The whole year of the Luanhe River was divided into 2 periods: (1) flood period and (2) non-flood period. The flood period was from May to September, and the non-flood period was from October to the next April. The mean monthly flow of each section was calculated

Table 2. EFR results of Dahekou (Luanhe River Upstream).

\begin{tabular}{|c|c|c|c|c|c|}
\hline Month & EFR $/\left(\mathrm{m}^{3} \cdot \mathrm{s}^{-1}\right)$ & Mean annual monthly flow $/\left(\mathrm{m}^{3} \cdot \mathrm{s}^{-1}\right)$ & Percentage & Grade & Recommended EFR $/\left(\mathrm{m}^{3} \cdot \mathrm{s}^{-1}\right)$ \\
\hline 1 & 0.84 & 0.79 & $106.0 \%$ & Optimum & 0.84 \\
\hline 2 & 0.72 & 0.86 & $83.8 \%$ & Optimum & 0.72 \\
\hline 3 & 0.86 & 1.59 & $54.1 \%$ & Outstanding & 0.86 \\
\hline 4 & 2.63 & 5.16 & $51.0 \%$ & Outstanding & 2.63 \\
\hline 5 & 2.03 & 2.67 & $76.0 \%$ & Outstanding & 1.03 \\
\hline 6 & 1.73 & 2.82 & $61.4 \%$ & Outstanding & 1.15 \\
\hline 7 & 1.15 & 3.56 & $32.3 \%$ & Fair & 1.19 \\
\hline 8 & 1.19 & 3.97 & $30.0 \%$ & Fair & 1.98 \\
\hline 9 & 1.98 & 3.24 & $61.2 \%$ & Outstanding & 1.82 \\
\hline 10 & 1.82 & 2.78 & $65.5 \%$ & Optimum & 0.79 \\
\hline 11 & 1.05 & 1.77 & $59.2 \%$ & Outstanding & Optimum \\
\hline 12 & 0.79 & 0.85 & $92.7 \%$ & & \\
\hline
\end{tabular}

Table 3. EFR results of Sandaohezi (Luanhe River Midstream).

\begin{tabular}{|c|c|c|c|c|c|}
\hline Month & $\mathrm{EFR} /\left(\mathrm{m}^{3} \cdot \mathrm{s}^{-1}\right)$ & Mean annual monthly flow $/\left(\mathrm{m}^{3} \cdot \mathrm{s}^{-1}\right)$ & Percentage & Grade & Recommended EFR $/\left(\mathrm{m}^{3} \cdot \mathrm{s}^{-1}\right)$ \\
\hline 1 & 3.5 & 4.45 & $78.6 \%$ & Optimum & 3.5 \\
\hline 2 & 3.92 & 4.98 & $78.8 \%$ & Optimum & 3.92 \\
\hline 3 & 4.72 & 12.32 & $38.3 \%$ & Excellent & 4.72 \\
\hline 4 & 10.86 & 28.67 & $37.9 \%$ & Excellent & 6.71 \\
\hline 5 & 6.71 & 13.19 & $50.9 \%$ & Excellent & 4.78 \\
\hline 6 & 4.78 & 18.12 & $26.4 \%$ & Minimum & 4.37 \\
\hline 7 & 2.83 & 43.70 & $6.5 \%$ & $\begin{array}{c}\text { Severe degra- } \\
\text { dation }\end{array}$ \\
\hline 8 & 6.69 & 66.93 & $10.0 \%$ & Minimum & 6.69 \\
\hline 9 & 8.95 & 39.22 & $22.8 \%$ & Minimum & 8.95 \\
\hline 10 & 10.11 & 25.42 & $39.8 \%$ & Excellent & 10.11 \\
\hline 11 & 3.6 & 14.88 & $24.2 \%$ & Good & 3.6 \\
\hline 12 & 3.61 & 6.01 & $60.1 \%$ & Optimum & 3.61 \\
\hline
\end{tabular}


Table 4. EFR results of Luanxian (Luanhe River Downstream).

\begin{tabular}{|c|c|c|c|c|c|}
\hline Month & $\mathrm{EFR} /\left(\mathrm{m}^{3} \cdot \mathrm{s}^{-1}\right)$ & Mean annual monthly flow $/\left(\mathrm{m}^{3} \cdot \mathrm{s}^{-1}\right)$ & Percentage & Grade & Recommended EFR $/\left(\mathrm{m}^{3} \cdot \mathrm{s}^{-1}\right)$ \\
\hline 1 & 15.29 & 32.58 & $46.9 \%$ & Outstanding & 15.29 \\
\hline 2 & 16.86 & 36.15 & $46.6 \%$ & Outstanding & 16.86 \\
\hline 3 & 27.09 & 51.50 & $52.6 \%$ & Outstanding & 27.09 \\
\hline 4 & 27.73 & 62.72 & $44.2 \%$ & Outstanding & 13.03 \\
\hline 5 & 13.03 & 37.79 & $34.5 \%$ & Fair & 12.4 \\
\hline 6 & 12.4 & 72.33 & $17.1 \%$ & Minimum & 46.4 \\
\hline 7 & 9.19 & 463.83 & $2.0 \%$ & Severe degradation & 65.7 \\
\hline 8 & 65.7 & 589.98 & $11.1 \%$ & Minimum & 60.26 \\
\hline 9 & 60.26 & 218.45 & $27.6 \%$ & Minimum & 64.59 \\
\hline 10 & 64.59 & 113.44 & $56.9 \%$ & Outstanding & 29.34 \\
\hline 11 & 29.34 & 78.87 & $37.2 \%$ & Excellent & 21.84 \\
\hline 12 & 21.84 & 43.95 & $49.7 \%$ & Outstanding & \\
\hline
\end{tabular}

by using the natural period series. And the EFRs accounting for the percentage of the mean monthly flow were computed and the grades were given in Tables 2-4, respectively. From Table 2 we could find that the EFR of Dahekou is relatively good and the grades of all the months are between fair and optimum, which indicates that EFR can meet the requirement of the basic ecological functions in the Luanhe upstream. From Tables 3 and 4 we can find that the ecological flows of July in Sandaohezi and Luanxian belong to the grade severe degradation, and it indicates that the ecological functions of the Luanhe midstream and downstream may be seriously destroyed. Taking into account the analysis results of the Tennant method and the flow needs of endemic aquatic life that includes brachymystax lenok in Dahekou and Sandaohezi, and crucian carp in Luanxian as mentioned above, the larger ones were selected as the recommended EFR values in the Luanhe (Tables 2-4).

\section{EFRSD Results of the Luanhe River}

The EFRSD of each section and the whole basin were computed after getting the recommended EFR values. Fig. 4 presents the whole river's EFRSD variation curve during the human-impacted period. And it can be seen that EFR could not be satisfied since 1980. And from 1980 to 1994 , the satisfactory degree was in the range

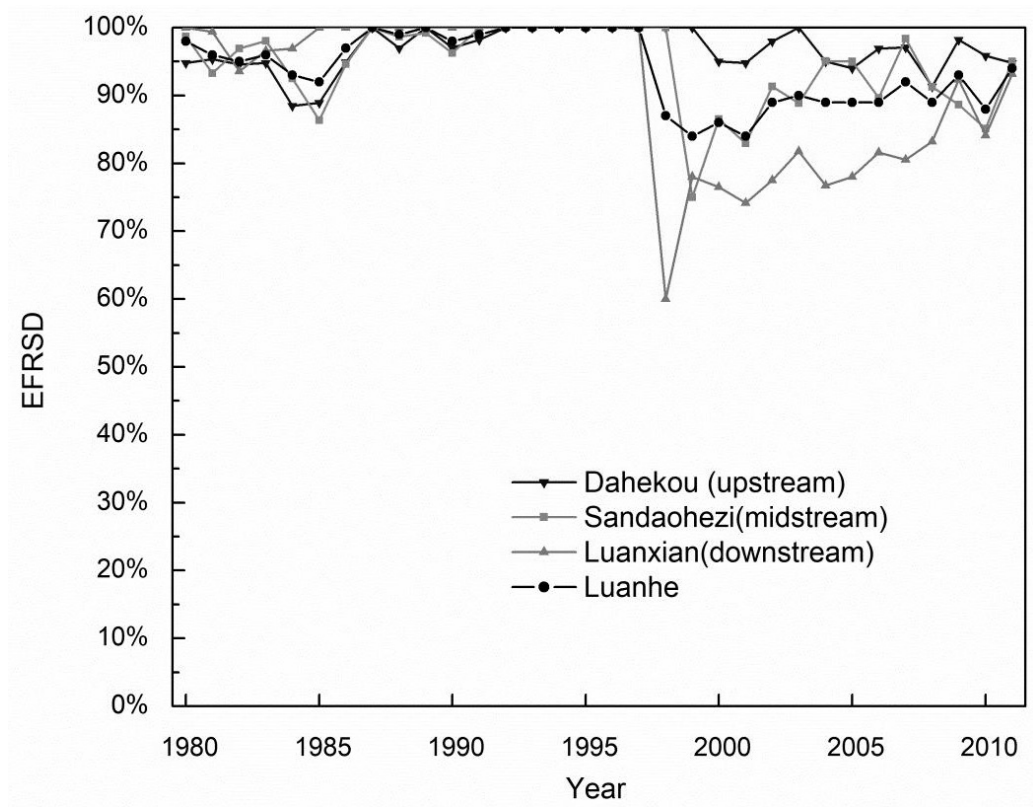

Fig. 4. EFRSD curve of Luanhe River during human impacted period. 
of $91.8 \%$ to $100 \%$, with an average satisfactory degree of $98.1 \%$; from 1995 to 1997 , the satisfactory degree was fully guaranteed (100\%); from 1998 to 2011, the satisfactory degree started to decline significantly, and the satisfactory degree was in the range of $84.3 \%$ to $94.3 \%$, with an average satisfactory degree of $89.0 \%$.

In the meantime, Fig. 4 shows the EFRSD curve in the Luanhe upstream, midstream and downstream during the human-impacted period. From Fig. 4 we can see that the satisfactory degree from large to small in the Luanhe River since 1980 in turn was Dahekou, Sandaohezi and Luanxian, which implies that the
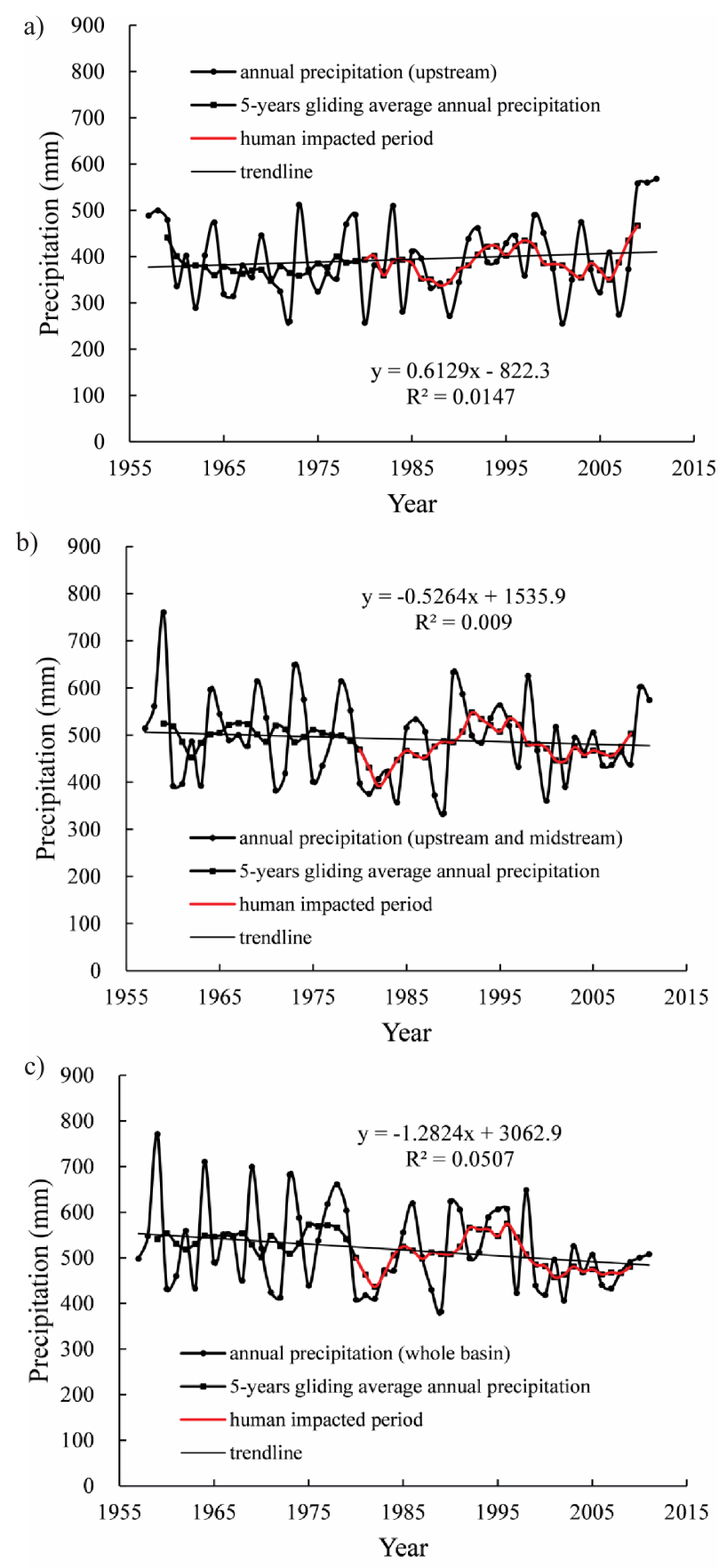

Fig. 5. Annual precipitation curves of Luanhe River upstream a), up-midstream b) and whole basin c).
EFRSD of the Luanhe from good to bad was the upstream, midstream and downstream.

\section{Driving Forces Analysis for the Luanhe River's EFRSD Deterioration}

Some factors were given to explain why the EFRSD of the Luanhe fluctuated, especially in decline. Fig. 5 demonstrates the annual precipitation and the 5-year gliding average process curve of the Luanhe from 1957 to 2011. Fig. 5a) shows that there is a little rising trend in the Luanhe River upper reaches. And from Fig. 5(b-c), there are little downward trends in the upper-middle reaches and the whole basin. This indicates that the natural precipitation in the upper reaches is increasing, while that in the mid-down reaches is decreasing. And this could reflect the fact that reduction in precipitation is a reason for the EFRSDs of the Luanhe midstream and downstream being worse than that of the Luanhe upstream. The whole basin's mean annual precipitation according to the natural period and 3 sub periods of the human-impacted period were calculated (Table 5). The results showed that: precipitation in the natural period was the most, $549.5 \mathrm{~mm}$; the period 1995 to 1997 was the second, $545.5 \mathrm{~mm}$; 1980 to 1994 was the third, $500 \mathrm{~mm}$; and 1998 to 2011 was the least, $487.1 \mathrm{~mm}$. The correlation coefficient between the mean annual precipitation and mean annual EFRSD in different periods was 0.816, which indicated that there was a significantly positive correlation between the EFRSD variation and the precipitation variation. And it could be used to explain the existence of the second inflexion point 1994 in Fig. 2a). So precipitation variation was one of the factors that the EFRSD of the Luanhe could not be satisfied in recent decades.

The large and medium-sized reservoirs total storage capacity (LMTSC) from 1955 to 2011 in the Luanhe was shown in Fig. 2b). From Fig. 2b), 2 inflexion points were found to be consistent with Fig. 2a) in the years 1979 (Panjiakou Reservoir, built in 1979, utilizable capacity $\left.1.95 \times 10^{9} \mathrm{~m}^{3}\right)$ and 1998 (Taolinkou Reservoir, built in 1998, utilizable capacity, $\left.7.06 \times 10^{8} \mathrm{~m}^{3}\right)$. And it indicated that the building and operating of water conservation projects had influenced the Luanhe River's flow regime during the last 40 years. And the completion of Taolinkou

Table 5. Mean annual precipitation and mean annual EFRSD of Luanhe River in four periods.

\begin{tabular}{|c|c|c|}
\hline Period/a & $\begin{array}{c}\text { Mean annual } \\
\text { precipitation/mm }\end{array}$ & $\begin{array}{c}\text { Mean annual } \\
\text { EFRSD/\% }\end{array}$ \\
\hline $1957-1979$ & 549.5 & 100 \\
\hline $1980-1994$ & 500.0 & 98.1 \\
\hline $1995-1997$ & 545.5 & 100 \\
\hline $1998-2011$ & 487.1 & 89.0 \\
\hline
\end{tabular}


Reservoir had also intensified the EFRSD destruction downstream, which was much more serious than the Luanhe upstream and midstream, for the river water was stopped and stored and transferred outside the basin. In the worst year, the EFRSD was only about $60 \%$ at Luanxian. And this can also be verified by Liu with the combined river impact factor (RI) and indicators of hydrological alteration (IHA) program based on the range of variability approach (RVA). Liu's results showed that the RIs of Panjiakou Reservoir and Taolinkou Reservoir were 0.09 and 0.20 , which belonged to 'extremely serious impact level' and 'serious impact level,' respectively. And the overall IHA of Panjiakou Reservoir was 0.88 . This indicated that the construction and operation of Panjiakou Reservoir and Taolinkou Reservoir have greatly changed the river's hydrological regime, altered the ecological process of fish migration and the benthic community structure, and destroyed the integrity of river habitat [40]. Therefore, the building and operating of these water conservation projects were important factors that could not be ignored when analyzing influencing factors of Luanhe River runoff reduction and health degradation. And the degree of ecological impact by each dam is as follows: Panjiakou $>$ Taolinkou $>$ Shandianhe (built in 1958 in upper reaches, utilizable capacity, $1.47 \times 10^{7} \mathrm{~m}^{3}$ ) [40].

Overexploitation of groundwater is also a driving force behind why the EFRSD of the Luanhe, especially downstream, could not be satisfied in recent years. The groundwater exploitation is mainly concentrated in the lower reaches of the Luanhe. During the last two decades, the exploiting rate of groundwater in the lower reaches is up to $96.0 \%$. And it has significantly altered the relationship between surface water and groundwater, increasing the river seepage supply and leading to the river flow decline, and thus in turn causing the EFRSD of the Luanhe, especially downstream, to decline.

So reduction in the natural rainfall, construction and operation of water conservation projects, and overexploitation of groundwater are the main driving forces leading to the Luanhe River's EFRSD deterioration. Among them, reduction in natural rainfall is mainly influenced by the EFRSDs of the Luanhe midstream and downstream. Building and operating those water conservation projects has an impact on the EFRSDs of the Luanhe upstream and midstream, but has the greatest impact on that of downstream. Besides, the overexploitation of groundwater also has intensified the EFRSD of Luanhe downstream destruction.

\section{Conclusions}

In this study, to overcome these deficiencies in the application of traditional methods for estimating EFR, an integrated method based on both the monthly 7Q10 method and biological analysis method was put forward for its simple modelling and small data requirement, and then reasonable EFR was obtained after a reasonable check by the Tennant method. Meanwhile, the concept and quantitative formula of the EFRSD were recommended and applied to the Luanhe. The conclusions of the study can be summarized as follows:

1) The integrated method composed by the monthly 7 Q10 and biological analysis methods can be successfully applied in regions where runoff was strongly influenced by human activities such as Luanhe River Basin.

2) The EFR of Luanhe River was significantly affected by human activities after 1979, and the EFRSD was distinctly damaged since 1998. After 1979, the EFRSD of the Luanhe from good to bad was the upstream, midstream, and downstream.

3) The driving forces for the EFRSD variation in the Luanhe were analyzed. And the reduction in the natural rainfall, construction and operating of water conservation projects, and overexploitation of groundwater are the main driving forces. Among them, reduction in the natural rainfall is mainly influenced by the EFRSDs of the Luanhe midstream and downstream. Building and operating those water conservation projects has an impact on the EFRSDs of the Luanhe upstream and midstream, but has the greatest impact on that of the downstream. Besides, the overexploitation of groundwater also has intensified the EFRSD of the Luanhe downstream destruction.

4) In order to improve the healthy state of the Luanhe River ecosystem, the countermeasures are pertinently put forward as follows: (1) Optimize operating rules of water conservation projects that include Daheiting, Panjiakou and Taolinkou reservoirs based on the aquatic ecosystem ecological requirements. And increase the flow of the Sandaohezi and Luanxian in the midstream and downstream to meet the ecological water requirements according to the EFRs in Tables 3 and Table 4. (2) Build a water-saving society in Luanhe River Basin, develop watersaving agriculture and industry, and reduce the rate of exploitation and utilization of regional water resources.

The outputs presented in this paper could provide a baseline for the ecological rehabilitation of the Luanhe. And this study could also serve as a reference for ecological flow studies in regions where runoff was strongly influenced by human activities.

\section{Acknowledgements}

This work was supported by the National Key Research and Development Program of China under grant No. 2016YFC0401306; the Ministry of Water Resources of China under grant No. 201101017; and the Applied Technology Research and Development Program of Heilongjiang Province under Grant No.GZ16B031. 


\section{Conflict of Interest}

The authors declare no conflict of interest.

\section{References}

1. DENG X., XU Y., HAN L., YU Z., YANG M., PAN G. Assessment of river health based on an improved entropybased fuzzy matter-element model in the Taihu Plain, China. Ecological Indicators, 57, 85, 2015.

2. SPEED R.A., LI Y., TICKNER D., HUANG H., NAIMAN R.J., CAO J., LEI G., YU L., SAYERS P., ZHAO Z. A framework for strategic river restoration in China. Water International, 41 (7), 998, 2016.

3. AHN K.H., MERWADE V. Quantifying the relative impact of climate and human activities on streamflow. Journal of Hydrology, 515 (515), 257, 2014.

4. KUHLMANN M.L., IMBIMBO H.R.V., OGURA L.L., VILLANI J.P., STARZYNSKI R., ROBIM M.D.J. Effects of human activities on rivers located in protected areas of the Atlantic forest. Acta Limnologica Brasiliensia, 26 (1), 60, 2014.

5. DONG W., CUI B., LIU Z., ZHANG K. Relative effects of human activities and climate change on the river runoff in an arid basin in northwest China. Hydrological Processes, 28 (18), 4854, 2014.

6. MCINTYRE N., BALLARD C., BRUEN M., BULYGINA N., BUYTAERT W., CLUCKIE I., DUNN S., EHRET U., EWEN J., GELFAN A. Modelling the hydrological impacts of rural land use change. Hydrology Research, 45 (6), 737, 2014.

7. BAWDEN A.J., BURN D.H., PROWSE T.D. Recent changes in patterns of western Canadian river flow and association with climatic drivers. Lancet, 46 (4), 1849, 2015.

8. EMAM A.R., KAPPAS M., HOSSEINI S.Z. Assessing the impact of climate change on water resources, crop productions and land degradation in a semi-arid river basin. Hydrology Research, 46 (6), 854, 2015.

9. MITTAL N., BHAVE A.G., MISHRA A., SINGH R. Impact of human intervention and climate change on natural flow regime. Water Resources Management, 30 (2), 685, 2015.

10. HGUMA D., LECONTE R., KRAU S., COTE P., BRISSETTE F. Water resources optimization method in the context of climate change. Journal of Water Resources Planning and Management, 141 (2), 04014051, 2015.

11. ZHANG Y., BLOCK P., HAMMOND M., KING A. Ethiopia's Grand Renaissance Dam: implications for downstream riparian countries. Journal of Water Resources Planning and Management, 141 (9), 05015002, 2015.

12. ADHIKARI U., NEJADHASHEMI A.P. Impacts of climate change on water resources in Malawi. Journal of Hydrologic Engineering, 21 (11), 05016026, 2016.

13. GAN T.Y., ITO M., HUELSMANN S., QIN X., LU X., LIONG S., RUTSCHMAN P., DISSE M., KOIVUSALO H. Possible climate change/variability and human impacts, vulnerability of drought prone regions, water resources and capacity building for Africa. Hydrological Sciences Journal, 61 (7), 1209, 2015.

14. LIANG S., GE S., WAN L., ZHANG J. Can climate change cause the Yellow River to dry up? Water Resources Research, 46 (2), 228, 2010.
15. DAI Z., DU J., CHU A., LI J., CHEN J., ZHANG X. Groundwater discharge to the Changjiang River, China, during the drought season of 2006: effects of the extreme drought and the impoundment of the Three Gorges Dam. Hydrogeology Journal, 18 (2), 359, 2009.

16. MEENU R., REHANA S., MUJUMDAR P.P. Assessment of hydrologic impacts of climate change in TungaBhadra river basin, India with HEC-HMS and SDSM. Hydrological Processes, 27 (11), 1572. 2013.

17. SUN C., CHEN Y., LI W., LI X., YANG Y. Isotopic time series partitioning of streamflow components under regional climate change in the Urumqi River, northwest China. Hydrological Sciences Journal, 61 (8), 1443, 2015.

18. KIRCHNER J.W., FENG X., NEAL C., ROBSON A.J. The fine structure of water-quality dynamics: the (highfrequency) wave of the future. Hydrological Processes, 18 (7), 1353, 2004.

19. YU M., LI Q., LU G., CAI T., XIE W., BAI X. Investigation into the impacts of the Gezhouba and the Three Gorges Reservoirs on the flow regime of the Yangtze River. Journal of Hydrologic Engineering, 18 (9), 1098, 2013.

20. YANG D., LI C., HU H., LIE Z., YANG S., KUSUDA T., KOIKE T., MUSIAKE K. Analysis of water resources variability in the Yellow River of China during the last half century using historical data. Water Resources Research, 1842 (40), 308, 2004.

21. ZHOU L., YING G., ZHAO J., YANG J., LI W., SHAN L. Trends in the occurrence of human and veterinary antibiotics in the sediments of the Yellow River, Hai River and Liao River in northern China. Environmental Pollution, 159 (7), 1877, 2011.

22. ZHANG Q., SINGH V.P., LI J, Eco-Hydrological requirements in arid and semiarid regions: case study of the Yellow River in China. Journal of Hydrologic Engineering, 18 (6), 689, 2013.

23. TENNANT D.L. Instream flow regimens for fish, wildlife, recreation and related environmental resources. Fisheries Management \& Ecology, 1 (4), 6, 1976.

24. BONER M.C., FURLAND L.P. Seasonal treatment and variable effluent quality based on assimilative capacity. Water Pollution Control Federation, 54 (10), 1408, 1982.

25. ZHANG Q., CUI Y., CHEN Y. Evaluation of ecological instream flow of the Pearl River basin, south China. Ecology and Environmental Sciences, 19 (8), 1828, 2010.

26. MATTHEWS R., BAO Y. The Texas method of preliminary instream flow determination. Rivers, 2 (4), 295, 1991.

27. PALAU A., ALCAZAR J. The basic flow method for incorporating flow variability in environmental flows. River Research and Applications, 28 (1), 93, 2012.

28. WANG X., XIA Z., TANG Z. Computation of ecological flow in the lower reaches of Yellow River. Journal of Hohai University(Natural Sciences), 37 (2), 153, 2009.

29. HUANG C., ZHAO J., WANG Z., SHANG W. Optimal hedging rules for two-objective reservoir operation: balancing water supply and environmental flow. Journal of Water Resources Planning and Management, 142 (12), 04016053, 2016.

30. GUO W., XIA Z. Study on ecological flow in the middle and lower reaches of the Yangtze River. Journal of Hydraulic Engineering, 53 (1), 107, 2007.

31. YU Z., YANG T., SCHWARTZ F.W. Water issues and prospects for hydrological science in China. Water Science and Engineering, 7 (1), 1, 2014.

32. FU X., DONG Z., LIU C., SHAN C., FANG Q., LIU Q. Analysis of runoff variation and its related driving forces 
in the Luanhe River Basin. South-to-North Water Transfers and Water Science \& Technology, 11 (5), 6, 2013.

33. XU W., DONG Z., HAO Z., LI D., REN L. River health evaluation based on the fuzzy matter-element extension assessment model. Polish Journal of Environmental Studies, 26 (3), 1353, 2017.

34. YAN D.H., WANG G., WANG H., QIN T. Assessing ecological land use and water demand of river systems: a case study in Luanhe River, North China. Hydrology and Earth System Sciences, 16 (8), 2469, 2012.

35. WANG W., SHAO Q., YANG T., PENG S., XING W., SUN F., LUO Y. Quantitative assessment of the impact of climate variability and human activities on runoff changes: a case study in four catchments of the Haihe River basin, China. Hydrological Processes, 27 (8), 1158, 2013.

36. ERIS E., AGRIRALIOGLU N. Homogeneity and trend analysis of hydrometeorological data of the Eastern Black
Sea Region, Turkey. Journal of Water Resource and Protection, 4 (2), 99, 2012.

37. ORTH D.J., MAUGHAN O.E. Evaluation of the "Montana method" for recommending instream flows in Oklahoma streams. Proceedings of the Oklahoma Academy of Science, 61, 62, 1981.

38. GUO Y.H., WANG G.X. Brachyrnastax lenok in Xiaoluan River: investigation on the survival environment and technique for domestication and raising. Hebei Fisheries, $8,45,2008$.

39. WANG W., YANG X.H., WANG Y.T. Ecological water requirements in the lower reaches of Luanhe Basin. Advances in Water Science, 20 (4), 560, 2009.

40. LIU J., YOU X., SHI X., BAO., MENG B. Hydrological and ecological effects of dams in Luanhe River Basin. Water Resources Protection, 32 (1), 23, 2016. 